\title{
Echocardiographic and Clinical Evaluation of Rheumatic Mitral Stenosis in Younger and Elderly Patients
}

\author{
Ramakrishna C. D.*, Placid Sebastian Kanattu \\ Department of Cardiology, Pariyaram Medical College, Kannur, India \\ Email: *drcdram@yahoo.com
}

How to cite this paper: Ramakrishna C.D. and Kanattu, P.S. (2017) Echocardiographic and Clinical Evaluation of Rheumatic Mitral Stenosis in Younger and Elderly Patients. International Journal of Clinical Medicine, 8, 128-135.

https://doi.org/10.4236/ijcm.2017.83012

Received: January 17, 2017

Accepted: March 12, 2017

Published: March 15, 2017

Copyright $\odot 2017$ by authors and Scientific Research Publishing Inc. This work is licensed under the Creative Commons Attribution International License (CC BY 4.0).

http://creativecommons.org/licenses/by/4.0/ (c) (i) Open Access

\begin{abstract}
Background: Rheumatic heart disease (RHD) is common form of heart disease among population, especially in developing countries like India. Mitral stenosis (MS) is majorly caused by rheumatic heart disease with mitral commissural adhesion, fibrosis and calcification of the chordae tendineae. The aim of present study was clinical and echocardiographic evaluation for mitral stenosis in RHD patients with different age group. Methods: This was a retrospective, nonrandomized, and single-centre study in which 203 consecutive patients presented rheumatic mitral stenosis. All the patients were divided into different age group viz. $<40$ years, 40 to 65 years and $>65$ years. Cardiovascular examination and echocardiography were done in each patient. Mitral valve area (MVA), mitral valve gradient (MVG) and left atrial (LA) diameter were assessed by echocardiography. Mitral valve score was recorded to analyse the degenerative changes in mitral valve structure. Results: A total of 203 patients (133 females) were enrolled and divided into three age groups. Patients with age above 65 years were considered as elderly and those patients with age below 40 years were considered as younger. Echocardiographic assessment showed mean 4.7 and $4.9 \mathrm{~cm}$ LA diameter, 0.92 and $0.86 \mathrm{~cm}^{2}$ MVA and 11.2 and $9.7 \mathrm{~mm} \mathrm{Hg} \mathrm{MVG}$ in younger and elderly patients respectively. Total mitral valve score has shown significant $(p<0.001)$ difference between younger and elder patients. Moreover, calcification and subvalvular thickening score with $>2$ had shown significant difference $(p<0.001)$ between younger and elderly patients. Conclusion: Present study provides unique contemporary data on characteristics and management of patients with rheumatic mitral stenosis. Majority of elderly patients are unsuitable for percutaneous commissurotomy due to degenerative changes in mitral valve structure.
\end{abstract}

\section{Keywords}

Percutaneous Commissurotomy, Rheumatic Heart Disease, Rheumatic Mitral Stenosis 


\section{Introduction}

Mitral stenosis (MS) causes an obstruction to blood flow from the left atrium to left ventricle. As a result, there is an increase in pressure within the left atrium, pulmonary vasculature, and right side of the heart, while the left ventricle is unaffected in isolated MS. Nearly all cases of MS are caused by rheumatic heart disease with mitral commissural adhesion; thickened, immobile mitral valve leaflets; and fibrosis, thickening, shortening, fusion, and calcification of the chordae tendineae. Infrequent causes of MS include mitral annular calcification and congenital mitral stenosis [1]. MS is highly prevalent in developing countries because of its association with the prevalence of rheumatic fever but is increasingly being identified in an unusual form in developed countries [2].

Two-thirds of the world's population live in developing countries with a high prevalence of rheumatic fever or rheumatic heart disease (RHD), resulting in a large population with mitral stenosis. In a survey of rheumatic fever in India [2], the mean age of presentation was 15 years, and two-thirds of the participants had signs of mitral stenosis, of whom half had limiting symptoms. Up to 30 million school children and young adults have chronic RHD worldwide, and nearly a third of these also have mitral stenosis [3].

Echocardiography is used to diagnose and judge stage of disease, assess mitral regurgitation, exclude that mimic mitral stenosis, and provide information about suitability for percutaneous balloon valvuloplasty (PBV). Both valve area and gradient can be accurately measured, but several measurements with more than one method are often needed to accurately estimate haemodynamics of the mitral valve. The most reliable method to calculate valve area is planimetry with $2 \mathrm{D}$ echocardiography cross-section images [4].

Even though the prevalence of mitral stenosis is high in India, the age-specific clinical and anatomical characteristics of the disease are not well studied among Indian patients. The present study was therefore undertaken with clinical and echocardiographic evaluation for Mitral Stenosis in RHD patients who attending the cardiology services at Pariyaram Medical College, Kannur, Kerala.

\section{Methods}

\subsection{Study Design and Patients Population}

A total of 203 consecutive patients presenting rheumatic mitral stenosis at the department of cardiology, Pariyaram Medical College, Kannur, Kerala from January 2012 to May 2014 were included in the present study. All the patients were divided into different age group. However, patients with grade $>2$ mitral regurgitation, more than mild lesion of the other valves and history of previous surgical commissurotomy either percutaneous or surgical were excluded from this study.

A record of physical findings was made and cardiovascular examination was done in each case. Echocardiography was carried out in all cases using a Philips, IE 33 Doppler Echocardiography system. Mitral valve area was assessed by 2D 
planimetry and pressure half time method [5]. To analyse the effect of mitral valve structure due to degenerative changes, we scored the echocardiographic study of each patient for: (a) leaflet mobility, (b) leaflet thickening, (c) subvalvar thickening, and (d) calcification. Table 1 shows the scoring system [6]. This study was approved by the institutional review board (IRB) and all patients signed the written informed consent.

\subsection{Statistical Analysis}

Patient baseline characteristics were presented as frequency and percentages. Differences between two point estimates were determined to be statistically significant at the 0.05 level using two-sided significance tests (z-tests).

\section{Results}

\subsection{Baseline Demographic Characteristics}

A total of 203 patients were divided into three age groups viz. $<40$ years (68 patients), 40 to 65 years ( 78 patients) and $>65$ years (57 patients). The mean age was 52 years (17 to 90 years). Patients with age above 65 years were considered

Table 1. Scoring of mitral valve characteristics from the echocardiographic examination [6].

\begin{tabular}{|c|c|}
\hline \multicolumn{2}{|c|}{ Variable (Scores) } \\
\hline \multicolumn{2}{|c|}{ Leaflet mobility } \\
\hline 1 & Highly mobile \\
\hline 2 & Reduced mobility \\
\hline 3 & Basal leaflet motion only \\
\hline 4 & Minimal motion \\
\hline \multicolumn{2}{|c|}{ Valve thickening } \\
\hline 1 & Near normal (4 - $5 \mathrm{~mm})$ \\
\hline 2 & Thickened tips \\
\hline 3 & Entire leaflet thickened $(5-8 \mathrm{~mm})$ \\
\hline 4 & Marked leaflet thickening $(>8-10 \mathrm{~mm})$ \\
\hline \multicolumn{2}{|c|}{ Calcification } \\
\hline 1 & Single area of brightness \\
\hline 2 & Scattered areas at leaflet margins \\
\hline 3 & Brightness extends to mid leaflets \\
\hline 4 & Extensive leaflet brightness \\
\hline \multicolumn{2}{|c|}{ Subvalvular thickening } \\
\hline 1 & Minimal chordal thickening \\
\hline 2 & Chordal thickening up to $1 / 3$ \\
\hline 3 & Distal third of chordae thickening \\
\hline 4 & Extensive thickening to pap muscle \\
\hline
\end{tabular}


as elderly and those patients with age below 40 years were considered as younger.

The past history of acute pulmonary oedema, rheumatic fever and atrial fibrillation were present in 19 (36\%), $11(20 \%)$ and $36(64 \%)$ for elder patients group while youngest group present with acute pulmonary oedema $4(6 \%)$, rheumatic fever 25 (37\%) and atrial fibrillation 6 (9\%) respectively. Cerebrovascular accident (CVA) due to infraction was present in 14 (25\%) of elderly compared to $2(3 \%)$ of younger patients (Table 2).

\subsection{Echocardiographic Examination}

Assessment of echocardiography showed mean left atrial (LA) diameter of 4.7 $\mathrm{cm}$, mitral valve area (MVA) of $0.92 \mathrm{~cm}^{2}$ and mitral valve gradient (MVG) of $11.2 \mathrm{~mm}$ of $\mathrm{Hg}$ in younger patients, while mean LA diameter $(4.9 \mathrm{~cm})$, MVA $\left(0.86 \mathrm{~cm}^{2}\right)$ and MVG $(9.7 \mathrm{~mm} \mathrm{Hg})$ were present in elderly patients (Table 3).

Table 2. Baseline characteristics of three age groups of patients with rheumatic mitral stenosis.

\begin{tabular}{ccccc}
\hline & \multicolumn{5}{c}{ Age group (years) } \\
\hline Parameters & $<40$ & $40-65$ & $>65$ & $\begin{array}{c}p \text { Value } \\
(<40 \text { Vs }>65)\end{array}$ \\
Number of patients & 68 & 52 & 34 & - \\
Females & $47(70 \%)$ & $52(68 \%)$ & $34(61 \%)$ & NS \\
Means NYHA Class & II & II & II & NS \\
Haroxysmal nocturnal dyspnea & $18(27 \%)$ & $22(29 \%)$ & $22(39 \%)$ & NS \\
Acute pulmonary oedema & $4(6 \%)$ & $11(14 \%)$ & $19(36 \%)$ & $<0.001$ \\
Rheumatic fever & $25(37 \%)$ & $23(70 \%)$ & $11(20 \%)$ & $<0.05$ \\
Cerebral vascular accident & $2(3 \%)$ & $9(12 \%)$ & $14(25 \%)$ & $<0.001$ \\
Atrial fibrillation & $6(9 \%)$ & $23(30 \%)$ & $36(64 \%)$ & $<0.001$ \\
Clinical features of & $44(66 \%)$ & $32(42 \%)$ & $24(43 \%)$ & $<0.01$ \\
Signs of pliable valve & $66(99 \%)$ & $70(91 \%)$ & $39(70 \%)$ & $<0.001$ \\
\hline pulmonary arterial hypertension & & & & \\
\hline
\end{tabular}

Values are expressed as n (\%). NYHA, New York Heart Association; Significance at $p<0.05$ calculated using a z-test comparing $<40$ years (younger) with $>65$ years (Elderly) patients; NS: Non-significant.

Table 3. Comparison of left atrial (LA) size, mitral valve area (MVA) and mitral valve gradient (MVG) of three age groups of patients with rheumatic mitral stenosis.

\begin{tabular}{cccc}
\hline & \multicolumn{3}{c}{ Age group (years) } \\
\hline Parameters & $<40$ & $40-65$ & $<65$ \\
\hline LA, mean (cm) & 4.7 & 4.5 & 4.9 \\
MVA, mean $\left(\mathrm{cm}^{2}\right)$ & 0.92 & 0.9 & 0.86 \\
MGV, means $(\mathrm{mm} \mathrm{Hg})$ & 11.2 & 10.4 & 9.7 \\
\hline
\end{tabular}




\subsection{Mitral Valve Score}

According to classification of mitral valve score as depicted in Table 1, the score of less than 8 was present in $88 \%, 54 \%$ and $23 \%$ of younger ( $<40$ years), 40 to 65 year old and elder ( $>65$ years) patients. However, $23 \%$ of elder patients had mitral valve score greater than 11 and only $2 \%$ patients had mitral valve score greater than 11 (Figure 1).

Higher calcification and subvalvular score $(>2)$ was present in $68 \%$ and $61 \%$ in elderly patients respectively. Though, only $3 \%$ and $13 \%$ patients with younger population present with higher calcification and subvalvular thickening, respectively (Figure 2).

\section{Discussion}

Mitral valve disease is a common cause of morbidity and mortality in patient over age of 65. Physical findings and natural history of rheumatic mitral stenosis may differ in older and younger patients. In addition, symptoms of mitral stenosis may be masked or exacerbated by coexistent coronary artery disease, pulmonary disease, hypertension, and other systemic disorders that commonly occur in older adults [7]. According to previous published reports for the treatment of mitral stenosis, the mean age of the patients ranged from 15 to 56 years. One third of the patients who undergo percutaneous mitral valvotomy are $>65$ years old [8] [9]. In the present single center study that excluded the patients who had

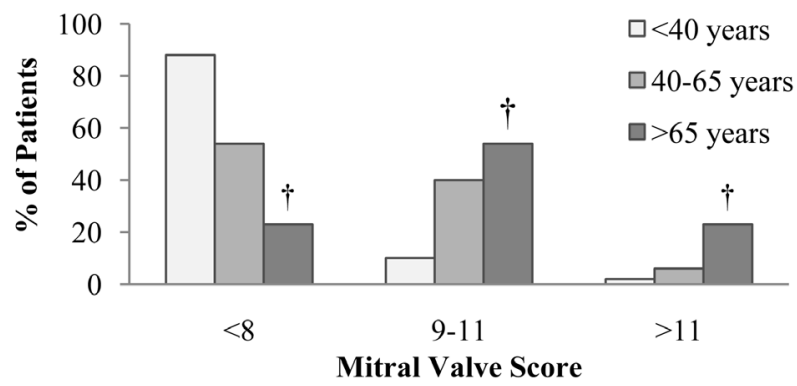

Figure 1. Comparison of mitral valve score $(<8$, between 9 to 11 and $>11)$ of three age groups of patients with rheumatic mitral stenosis. ${ }^{\dagger}$ The $P<0.001$ calculated using a z-test comparing $<40$ years (younger) with $>65$ years (Elderly) patients.

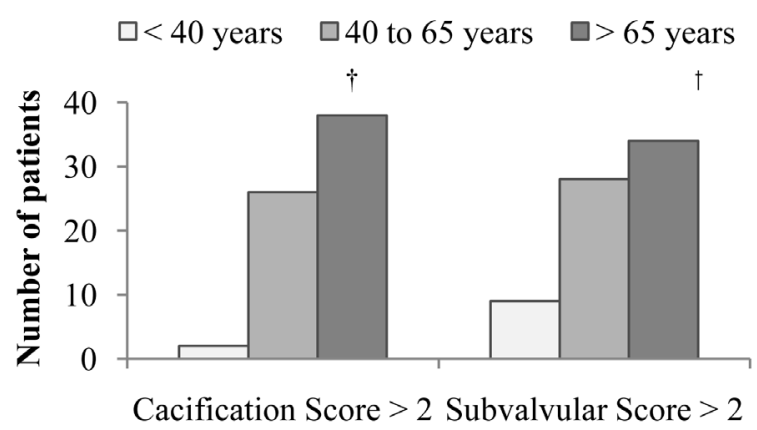

Figure 2. Calcification score and subvascular score having $>2$ of three age groups of patients with rheumatic mitral stenosis. ${ }^{\dagger}$ The $\mathrm{P}<0.001$ calculated using a $\mathrm{z}$-test comparing $<40$ years (younger) with $>65$ years (Elderly) patients. 
undergone surgical or percutaneous commissurotomy, 28\% were above the age of 65 years, the oldest being 90 years of age. Only two patients (3\%) were below 18 years. Two thirds of patients were females. Mean duration of dominant symptom of dyspnoea on exertion was 4.9 years that is comparable to younger patients which indicates that the disease may remain latent for many decades and may be participated by arrhythmias like atrial fibrillation which is significantly higher in elderly patients. Incidence of acute pulmonary edema was significantly higher in elderly patients (36\%) than younger group (6\%). Difference could be due to multiple factors like higher incidence of atrial fibrillation, lower atrial compliance, presence of diastolic dysfunction and other co morbid conditions like systemic arterial hypertension or coronary artery disease. This is contrary to earlier observations that acute pulmonary oedema occurs in the early stages of the disease in the younger patients. Average age of patients with acute pulmonary oedema in Wood's series was 32 years [10].

History of rheumatic fever is present in $60 \%$ of cases [10]. In our study $37 \%$ of younger patients gave history of rheumatic fever where as only $20 \%$ of elderly group could remember about the occurrence of rheumatic fever in childhood. Incidence of cerebrovascular accident was higher among elderly group than younger ( $25 \%$ vs $3 \%$ ) probably due to higher incidence of atrial fibrillation. Trial fibrillation is the most common complication (40\%) of mitral stenosis [10]. Aging is reported as an independent risk factor for the genesis of atrial fibrillation in mitral stenosis [11]. Moreover, Previous study showed patients who developed AF were older and had higher mitral echo score but equal mitral valve area and left atrial size [12]. According to our study, AF was significantly more common in elderly group (64\% Vs $9 \%, P=<0.001$ ). Tandon et al. (2010) found more severe pulmonary vascular changes in younger patient [13]. These results have support to Sinha et al. (1997) findings that mean pulmonary arterial pressure and pulmonary vascular resistance are greater in juvenile patients with mitral stenosis when compared with adults [14]. In our study also clinical evidences of pulmonary arterial hypertension, electrocardiographic evidence of right ventricular hypertrophy, radiology evidence of main pulmonary artery dilatation; electrocardiographic feature of right ventricular dilatation (RVIDd $>2.6 \mathrm{~cm}$ ) and pulmonary arterial systolic of more than $>50 \mathrm{mmHg}$ were significantly more common among younger age group.

On echocardiographic evaluation, elderly patients had left atrial size of $4.9 \mathrm{~cm}$ while it was $4.7 \mathrm{~cm}$ in the younger group. Mean mitral value area was $0.86 \mathrm{~cm}^{2}$ in the elderly and $0.92 \mathrm{~cm}^{2}$ in younger group. In addition, mean mitral valve gradient was $9.7 \mathrm{~mm} \mathrm{Hg}$ in elderly and $11.2 \mathrm{~mm} \mathrm{Hg}$ in younger patients. Despite similarity in mitral valve area and mitral valve gradient, total mitral valve score of $<8$ was statistically more common among younger group and $>11$ was statistically more common among elderly group (Figure 1). Fawzy et al. has shown that lower in mitral echo score, mitral valve area and higher Doppler mitral valve gradient were observed in younger ( $<20$ years) when compared to adults ( $>20$ years) [15]. Older patients had more severe degree of mitral stenosis, with 
higher mitral valve degenerative changes. After balloon dilatation the younger patients achieved a greater increase in valve area. Moreover, procedural success was higher in the younger group with a greater increase in mitral valve area but complications were similar in both groups. In our study among elderly group, approximately $80 \%$ of patients were not suitable for closed mitral valvotomy or percutaneous commissurotomy. Complications of balloon valvotomy were more common in the older patients [16].

\section{Conclusion}

In older patients there is a greater tendency for valve degenerative change in addition to commissural fusion, and such patients often have co-morbidities. Majority of younger patients ( $88 \%$ ) have Wilkin's score of $<8$, while most of elderly patients (77\%) have score more than 9 despite having similar mean mitral valve area and mean mitral gradient. Thus, in older patients, improvement may be made by palliative treatment for those unsuitable for surgery.

\section{References}

[1] Chandrashekhar, Y., Westaby, S. and Narula, J. (2009) Mitral Stenosis. The Lancet, 374, 1271-1283. https://doi.org/10.1016/S0140-6736(09)60994-6

[2] Padmavati, S. (2001) Rheumatic Fever and Rheumatic Heart Disease in India at the Turn of the Century. Indian Heart Journal, 53, 35-37.

[3] Waller, B.F., Howard, J. and Fess, S. (1994) Pathology of Mitral Valve Stenosis and Pure Mitral Regurgitation-Part I. Clinical Cardiology, 17, 330-336. https://doi.org/10.1002/clc.4960170611

[4] Messika-Zeitoun, D., Fung Yiu, S., Cormier, B., Iung, B., Scott, C., Vahanian, A., Tajik, A.J. and Enriquez-Sarano, M. (2003) Sequential Assessment of Mitral Valve Area during Diastole Using Colour M-Mode Flow Convergence Analysis: New Insights into Mitral Stenosis Physiology. European Heart Journal, 24, 1244-1253. https://doi.org/10.1016/S0195-668X(03)00208-2

[5] Kang, W.S., Choi, J.W., Kang, J.E., Chung, J.W. and Kim, S.H. (2013) Determination of Mitral Valve Area with Echocardiography, Using Intra-Operative 3-Dimensional versus Intra- \& Post-Operative Pressure Half-Time Technique in Mitral Valve Repair Surgery. Journal of Cardiothoracic Surgery, 8, 98.

https://doi.org/10.1186/1749-8090-8-98

[6] Wilkins, G.T., Weyman, A.E., Abascal, V.M., Block, P.C. and Palacios, I.F. (1988) Percutaneous Balloon Dilatation of the Mitral Valve: An Analysis of Echocardiographic Variables Related to Outcome and the Mechanism of Dilatation. British Heart Journal, 60, 299-308. https://doi.org/10.1136/hrt.60.4.299

[7] Segal, B.L. (2003) Valvular Heart Disease, Part 2. Mitral Valve Disease in Older Adults. Geriatrics, 58, 26-31.

[8] Skagen, K., Hansen, J.F. and Olesen, K.H. (1978) Closed Mitral Valvulotomy after the Age of Fifty. Scandinavian Journal of Thoracic and Cardiovascular Surgery, 12, 85-89. https://doi.org/10.3109/14017437809100354

[9] Tuzcu, E.M., Block, P.C., Griffin, B.P., Newell, J.B. and Palacios, I.F. (1992) Immediate and Long-Term Outcome of Percutaneous Mitral Valvotomy in Patients 65 Years and Older. Circulation, 85, 963-971. https://doi.org/10.1161/01.CIR.85.3.963

[10] Wood, P. (1954) An Appreciation of Mitral Stenosis. I. Clinical Features. British 
Medical Journal, 1, 1051-1063. https://doi.org/10.1136/bmj.1.4870.1051

[11] Diker, E., Aydogdu, S., Ozdemir, M., Kural, T., Polat, K., Cehreli, S., Erdogan, A. and Goksel, S. (1996) Prevalence and Predictors of Atrial Fibrillation in Rheumatic Valvular Heart Disease. American Journal of Cardiology, 77, 96-98. https://doi.org/10.1016/S0002-9149(97)89145-X

[12] Eid Fawzy, M., Shoukri, M., Al Sergani, H., Fadel, B., Eldali, A., Al Amri, M. and Canver, C.C. (2006) Favorable Effect of Balloon Mitral Valvuloplasty on the Incidence of Atrial Fibrillation in Patients with Severe Mitral Stenosis. Catheterization and Cardiovascular Interventions. Official Journal of the Society for Cardiac Angiography \& Interventions, 68, 536-541. https://doi.org/10.1002/ccd.20770

[13] Tandon, H.D. and Kasturi, J. (1975) Pulmonary Vascular Changes Associated with Isolated Mitral Stenosis in India. British Heart Journal, 37, 26-36.

https://doi.org/10.1136/hrt.37.1.26

[14] Sinha, N., Kapoor, A., Kumar, A.S., Shahi, M., Radhakrishnan, S., Shrivastava, S. and Goel, P.K. (1997) Immediate and Follow Up Results of Inoue Balloon Mitral Valvotomy in Juvenile Rheumatic Mitral Stenosis. The Journal of Heart Valve Disease, 6, 599-603.

[15] Fawzy, M.E., Stefadouros, M.A., Hegazy, H., Shaer, F.E., Chaudhary, M.A. and Fadley, F.A. (2005) Long Term Clinical and Echocardiographic Results of Mitral Balloon Valvotomy in Children and Adolescents. Heart, 91, 743-748. https://doi.org/10.1136/hrt.2004.040766

[16] Shaw, T.R., Sutaria, N. and Prendergast, B. (2003) Clinical and Haemodynamic Profiles of Young, Middle Aged and Elderly Patients with Mitral Stenosis Undergoing Mitral Balloon Valvotomy. Heart, 89, 1430-1436.

https://doi.org/10.1136/heart.89.12.1430

Submit or recommend next manuscript to SCIRP and we will provide best service for you:

Accepting pre-submission inquiries through Email, Facebook, LinkedIn, Twitter, etc. A wide selection of journals (inclusive of 9 subjects, more than 200 journals) Providing 24-hour high-quality service User-friendly online submission system Fair and swift peer-review system Efficient typesetting and proofreading procedure Display of the result of downloads and visits, as well as the number of cited articles Maximum dissemination of your research work

Submit your manuscript at: http://papersubmission.scirp.org/

Or contact ijcm@scirp.org 